Journal of Advanced Research in Fluid Mechanics and Thermal Sciences

Journal homepage: www.akademiabaru.com/arfmts.html ISSN: 2289-7879

\title{
Torrefaction Temperature and Holding Time Effect on Khaya Senegalensis Biomass
}

\author{
Adli Azimi Abdul Rahman ${ }^{1}$, Ras Izzati Ismail ${ }^{1,{ }^{*}}$, Abdul Razak Shaari ${ }^{1}$ \\ Department of Mechanical Engineering Technology, Faculty of Engineering Technology, Universiti Malaysia Perlis, 02100 Padang Besar, Perlis, \\ Malaysia
}

ARTICLE INFO ABSTRACT

Article history:

Received 7 October 2020

Received in revised form 5 February 2021

Accepted 10 February 2021

Available online 16 March 2021

\section{Keywords:}

Torrefaction; a thermal pretreatment; biomass; Khaya senegalensis; temperature; holding time; fuel pellets

\begin{abstract}
Khaya senegalensis is fast growing plant, can be planted in marginal land and grow easily in Malaysia. Therefore, it has the potential to be developed as dedicated energy crops. This study was conducted to determine the effect of torrefaction in upgrading the quality of Khaya senegalensis biomass. Torrefaction has been known as one of the most promising pre-treatments for biomass. In this experiment, the biomass sample was torrefied in the muffle furnace at four different temperatures $(225,250,275$ and $300^{\circ} \mathrm{C}$ ) and three durations (30,60 and 90 minutes). The results show that both torrefaction temperature and duration posed strong impact on the biomass quality. It was found that the volatile matters of the biomass reduce significantly as the torrefaction severity increase. On the other hand, the ash and carbon content increase with the increasing temperature and duration. Most importantly the calorific value of the biomass sample amplifies to $22.26 \mathrm{Mj} / \mathrm{kg}$ from $16.11 \mathrm{Mj} / \mathrm{kg}$ of untreated sample when torrefied at $300^{\circ} \mathrm{C}$ for 90 minutes.
\end{abstract}

\section{Introduction}

Biomass has been used traditionally in the rural area for burning purpose for the household activities. However, with the increasing concern about global warming, biomass has been introduced as the bioenergy feedstock that can generate energy efficiently. Now, biomass has entered the energy production industry as a strong candidate for renewable source of energy. According to The European Environmental Agency, 13\% out of 1.8 billion tons of European energy consumption in the 2020 will be contributed by biomass industry. In conjunction with that, it is estimated that the demand for biomass as a feeding material for heat and power will be amplified to 5-7 billion tons in 2050 [1]. Biomass is among the great sources of renewable energy considering of the ability to be replanted and contributes very low quantity of $\mathrm{CO}_{2}$ emissions [1].

The biomass feedstock may come from various sources such as agricultural wastes, forestry residues, and dedicated energy crops. Biomass raw material has their own physical and biochemical characteristics that definitely will influence its performance as bioenergy feedstock [2]. Currently,

\footnotetext{
* Corresponding author.

E-mail address: rasizzati@unimap.edu.my

https://doi.org/10.37934/arfmts.81.1.150157
} 
among the other sources of biomass, dedicated energy crops have become the most promising resources of biomass energy. It is due to the physicochemical and agronomic characteristics of dedicated energy crops that will benefit the energy conversion process. More to the point, dedicated energy crops can reduce the overall processing cost including transportation and storage as the processing site can be built near to the plantation and the systems (plantation and process) can be integrated.

Dedicated energy crops have been proven in the developed countries as a promising option in widening of raw biomass energy resources. Dedicated energy crops typically possess certain important characteristics such fast growing, can be planted in marginal land, and high biomass production [3]. Besides that, another important criterion is their physicochemical compositions has strong influence on the energy density and their performance in the energy conversion process. Among established dedicated energy crops that have been commercially planted for energy purposes are poplar, willow, eucalyptus, and miscanthus [4].

Malaysia has been granted with many plant species that has strong potential as energy crop even though less explored [5]. Among the species that has been identified to be listed as dedicated energy crops species are Leucaena leucocephala, Azadirachta excelsa, and Khaya senegalensis. In this paper, the focus is on the Khaya senegalensis. Khaya senegalensis is a plant species that belongs to Meliaceae family and native in Africa. The matured plant can grow up to 15-30 m height and about 1 $\mathrm{m}$ in diameter. The wood is used for construction purposes, household apparatuses, and domestic fuel wood. In addition, the bark of the tree is used to traditionally to cure several illnesses such as headache, stomach pain and malaria fever [6]. However, in Malaysia, Khaya senegalensis has been introduced as landscape and shade tree. Khaya senegalensis is known as fast growing plant that can be cultivated on marginal soil. These are important characteristics of energy crops so that it will not compete to utilize the agriculture land. It was reported that with the proper irrigation and fertilization, this plant can reach $400 \mathrm{~cm}$ in height and produce $18 \mathrm{~kg}$ biomass per plant in just one year [7].

It is known that biomass energy has some physical and biochemical challenge that need to be overcame before can be established as energy crops and ready for commercialization. Among the major challenge in utilization of biomass include low energy density, high in moisture, and less uniform physicochemical characteristics [8]. These properties give some trouble especially in biomass thermochemical conversion [9]. Therefore, the biomass supposedly undergoes thermal, biological or chemical pretreatments to improve its properties [10].

Thermal pretreatment has become a popular method among researcher and biomass energy producer as it is easy to set up, more economical and give high quality biomass feedstock. One of the most common thermal biomass pretreatments is torrefaction. Torrefaction is a mild pyrolysis that usually the imposition temperature is around $200-300^{\circ} \mathrm{C}[11]$. This process will remove the moisture in the biomass sample and alters the lignocellulosic composition. In this process most of the hemicellulose will be removed or at least reduced depending on the severity of the torrefaction process as well as the plant morphology.

Torrefaction treatment on many species showed significant improvement of the biomass quality such as low volatile matters, high carbon content and importantly high calorific value. The composition of torrefied biomass is more preferable as it increases the lignin content per gram sample [12]. Currently, biomass will be transported, stored, and traded in the densified form either pellet or briquette as this can reduce the cost and amplify the quality for energy purposes. Hence, it is proven that torrefied biomass that contains high lignin and low hemicellulose compositions give good quality of biomass energy pellet. Furthermore, the torrefied biomass pellet has higher calorific 
value, lower the hygroscopicity, and emit less carbon monoxide gas which is very good for thermal energy conversion process [13].

\section{Methodology}

\subsection{Biomass Sample}

The matured Khaya senegalensis available at Institute of Agro-technology (INSAT), UniMAP was cutback and then allowed to sun dry for 1 week. The wood then was shredded before grinded using grinding machine at Faculty of Engineering Technology, UniMAP. The ground biomass was sieved to obtain uniform particle size of $1 \mathrm{~mm}$ Khaya senegalensis biomass.

\subsection{Torrefaction Experiment}

The uniform particle size of Khaya senegalensis biomass was placed in the crucible before heated in the muffle furnace at desired torrefaction temperature which are $225,250,270$, and $300^{\circ} \mathrm{C}$. The samples were allowed to be heated for 30,60 and 90 minutes in order to quantify the effect of both torrefaction temperature and time on Khaya senegalensis biomass.

\subsection{Biomass Characterization}

Proximate analysis was performed to establish some important quality of the biomass sample which were moisture content, volatile matters, ash content, and carbon content. The moisture content was determined using ASTM D 4442-07 standard method for wood and wood-based materials method. The weighed sample will be dried in the oven at $105^{\circ} \mathrm{C}$ for 24 hours. The moisture was calculated by the difference between initial and final weight. The ash percentage will be determined by igniting the sample at $575^{\circ} \mathrm{C}$ for 5 hours in the furnace (ASTM-E1755). The volatile matter will be quantified using ASTM-E872 method where the sample will be burned at $950^{\circ} \mathrm{C}$ for 7 minutes. The total fixed carbon content will be calculated using the following equation

$F C=100-(\% M C+\% V M+\% A C)$

Calorific value of the samples was determined by a bomb calorimeter as stated in the ASTM Standard D 5865 procedure. Approximately $0.5 \mathrm{~g}$ of the sample was weighed and placed in a crucible immersed in distilled water inside the bomb calorimeter. The calorific value was recorded as MJ per $\mathrm{kg}$ of the biomass sample.

\section{Result and Discussion}

\subsection{Proximate Analysis of Torrefied Khaya Senegalensis Biomass}

Proximate analysis result of torrefied Khaya senegalensis biomass is shown in Table 1. Generally, it was found that there is a significant change in volatile matter, ash content and carbon content of torrefied Khaya senegalensis. The volatile matters of the treated biomass steadily reduce as the torrefaction severity increase. It was found that both temperature and duration of torrefaction give significant alteration in the volatile matters' percentage of the biomass. The volatile matters drop significantly after being torrefied at $225^{\circ} \mathrm{C}$ for 60 and 90 minutes. The value continues to decrease when the torrefaction severity increase. The volatile matters of biomass torrefied at $275^{\circ} \mathrm{C}$ for 90 
minutes drops about $40 \%$ as compared to the untreated biomass. The lowest volatile matters recorded was $52.32 \%$ of the biomass that had been torrefied at $300^{\circ} \mathrm{C}$ for 90 minutes.

The reduction in volatile matters percentage of biomass after experienced the torrefaction treatment happens to almost any types of biomass. For instance, it was found that the volatile matters of torrefied oil palm frond reduced to $46.37 \%$ of volatile matters from $79.37 \%$ in the raw sample. The same observation was recorded for Leucaena leucocephala biomass. The volatile matters reduced about $40 \%$ from the untreated sample [14]. The same pattern of reducing volatile matters after torrefaction experiment was reported on Norway spruce biomass. The volatile matters of three different parts of the plant namely stem wood, stump and bark consistently drop as the torrefaction severity increase [15].

The ash content of raw Khaya senegalensis biomass is $4.40 \%$ (Table 1 ) and it is considerably low for woody biomass. It was reported that ash content of some common biomass utilized for energy purposes such as eucalyptus, pine, poplar and oak is between $0.5-3 \%$ [16]. The study on some other biomass from forest residue such as willow, bark, and red canary grass also contain low percentage of ash content which is between $0.3-2.4 \%$ [17]. As can be seen in the Table 1, the ash content of torrefied Khaya senegalensis biomass is suggestively affected by the torrefaction temperature and time. As the temperature increase, the ash content of the biomass also increases significantly. The ash content increase drastically to 14.38 and $12.74 \%$ as the temperature of $250^{\circ} \mathrm{C}$ was imposed for 60 and 90 minutes, respectively. The percentage continues to increase about $30 \%$ as the severity of torrefaction was intensified to $275^{\circ} \mathrm{C}$ for 60 minutes. However, beyond this torrefaction condition, the ash content of the biomass is stable even the torrefaction severity increase up to $300^{\circ} \mathrm{C}$ for 90 minutes.

The same phenomena were observed for other species of biomass experienced the torrefaction treatment. For instance, the ash content of torrefied cotton stalk is $11.8 \%$, increase about $40 \%$ as compared to the ash content of the raw material [18]. This trend also reported for the torrefied agriculture residues; napier grass, rice straw, cassava stalks, and corn cob. The ash content of all these biomasses increase after imposed with torrefaction treatment in the range of $20-30 \%$ as compared to the untreated biomass [19]. Ash content of biomass is the inorganic compound left in the combustion crucible that do not involve in the combustion process. Therefore, high ash content usually will reduce the energy density of the biomass. Not just that, high ash content also will give some trouble during the energy conversion process. High ash content material will generate higher deposition inside the boiler or gasifier that need to be cleaned up to maintain the efficacy of the equipment. Hence, the reduction of biomass ash content can avoid frequent equipment maintenance and can improve the energy conversion process [20].

Another important biomass parameter is carbon content. Carbon content is much related to the energy density of biomass. As can be seen in the Table 1, the carbon content of Khaya senegalensis is noticeably increased to about $80 \%$ as the severity of the torrefaction condition increased. Undeniably, that the torrefaction process can amplify the total carbon content of the biomass as the sample was burned at high temperature like the pyrolysis process. Increase in carbon content of torrefied biomass is related to the depletion of hemicellulose and some of the cellulose. This condition will increase the lignin composition per unit weight of the biomass sample. It is known that carbon content and lignin composition are among the determining factor of calorific value [21]. Therefore, torrefied biomass with high carbon content is much expected to possess higher calorific value

In general, from the result presented in Table 1, it was found that when the severity of torrefaction increases the carbon content and ash content of the sample increase accordingly while the volatile matters reduce significantly. Biomass that was exposed to high temperature for certain 
period will be subjected to some changes in their physicochemical properties. The torrefaction temperature range $\left(200-300^{\circ} \mathrm{C}\right)$ can initiate some destructive reactions such as decomposition, devolatilization and carbonization. The color of the biomass will change due to the decomposition of hemicellulose [22]. The weight lost during torrefaction process also contributed by the evaporation of bound water and some volatile matters. The amount of the volatile matters released during torrefaction process basically depend on the temperature, duration, and the physicochemical composition of the biomass. The increase in temperature and duration will lead to the carbonization reaction and high volatile matters emancipation that will result in good quality of feedstock biomass production especially for thermal energy conversion purposes [23].

\begin{tabular}{|c|c|c|c|c|}
\hline & & \multicolumn{3}{|c|}{ Proximate analysis (\%) } \\
\hline & & $\begin{array}{l}\text { Volatile } \\
\text { matters }\end{array}$ & $\begin{array}{l}\text { Ash } \\
\text { content }\end{array}$ & $\begin{array}{l}\text { Carbon } \\
\text { content }\end{array}$ \\
\hline \multicolumn{2}{|c|}{$\begin{array}{l}\text { K. sinegalensis } \\
\text { Torrefaction }\end{array}$} & 83.07 & 4.40 & 12.53 \\
\hline $225^{\circ} \mathrm{C}$ & $30 \mathrm{~min}$ & 87.89 & 4.11 & 8.00 \\
\hline $225^{\circ} \mathrm{C}$ & $60 \mathrm{~min}$ & 83.75 & 5.62 & 10.63 \\
\hline $225^{\circ} \mathrm{C}$ & $90 \mathrm{~min}$ & 75.73 & 8.25 & 16.01 \\
\hline $250^{\circ} \mathrm{C}$ & $30 \mathrm{~min}$ & 80.30 & 6.68 & 13.03 \\
\hline $250^{\circ} \mathrm{C}$ & $60 \mathrm{~min}$ & 69.84 & 14.38 & 15.78 \\
\hline $250^{\circ} \mathrm{C}$ & $90 \mathrm{~min}$ & 71.46 & 12.74 & 15.81 \\
\hline $275^{\circ} \mathrm{C}$ & $30 \mathrm{~min}$ & 81.71 & 9.74 & 8.55 \\
\hline $275^{\circ} \mathrm{C}$ & $60 \mathrm{~min}$ & 61.99 & 19.38 & 18.63 \\
\hline $275^{\circ} \mathrm{C}$ & $90 \mathrm{~min}$ & 58.09 & 20.94 & 20.97 \\
\hline $300^{\circ} \mathrm{C}$ & $30 \mathrm{~min}$ & 59.17 & 22.21 & 18.62 \\
\hline $300^{\circ} \mathrm{C}$ & $60 \mathrm{~min}$ & 60.36 & 23.25 & 16.39 \\
\hline $300^{\circ} \mathrm{C}$ & $90 \mathrm{~min}$ & 52.32 & 23.78 & 23.90 \\
\hline
\end{tabular}

Calorific value is the most important parameter of any biomass to be listed as potential energy crop. Table 2 shows the calorific value of raw and torrefied Khaya senegalensis biomass. As shown in the table, the calorific value of Khaya senegalensis increase steadily with the increase of torrefaction severity. The calorific value starts to increase significantly to $17.73 \mathrm{MJ} / \mathrm{kg}$ as the sample was torrefied at $225^{\circ} \mathrm{C}$ for 60 minutes. Then, the value continues to increase after the temperature was increased to $275^{\circ} \mathrm{C}$. The highest calorific value which is $22.26 \mathrm{MJ} / \mathrm{kg}$ was obtained when the biomass sample was exposed to $300^{\circ} \mathrm{C}$ of torrefaction temperature for 90 minutes.

This result is accordingly with the carbon content and volatile matters result. The value of carbon content and volatile matters is interrelated even though the relationship is complex. Biomass with low volatile matters, usually contain higher amount of carbon and will also has high calorific value. Other plant species imposed with torrefaction pretreatment also resulting in some good product. For instance, the torrefied Leucaena leucocephala has about $20 \%$ higher calorific value as compared to the raw biomass [24]. The similar pattern is reported for other biomass such as oil palm [11], willow [25] and pine [26]. 


\begin{tabular}{|c|c|c|}
\hline \multicolumn{3}{|c|}{$\begin{array}{l}\text { Calorific value of torrefied Khaya } \\
\text { senegalensis at different temperature } \\
\text { and time }\end{array}$} \\
\hline \multicolumn{2}{|c|}{ Sample } & $\begin{array}{l}\text { Calorific value } \\
(\mathrm{MJ} / \mathrm{kg})\end{array}$ \\
\hline \multicolumn{2}{|c|}{ K. sinegalensis } & 16.11 \\
\hline $225^{\circ} \mathrm{C}$ & $30 \mathrm{~min}$ & 16.81 \\
\hline $225^{\circ} \mathrm{C}$ & $60 \mathrm{~min}$ & 17.73 \\
\hline $225^{\circ} \mathrm{C}$ & $90 \mathrm{~min}$ & 18.11 \\
\hline $250^{\circ} \mathrm{C}$ & $30 \mathrm{~min}$ & 17.44 \\
\hline $250^{\circ} \mathrm{C}$ & $60 \mathrm{~min}$ & 19.06 \\
\hline $250^{\circ} \mathrm{C}$ & $90 \mathrm{~min}$ & 19.09 \\
\hline $275^{\circ} \mathrm{C}$ & $30 \mathrm{~min}$ & 17.86 \\
\hline $275^{\circ} \mathrm{C}$ & $60 \mathrm{~min}$ & 20.63 \\
\hline $275^{\circ} \mathrm{C}$ & $90 \mathrm{~min}$ & 21.44 \\
\hline $300^{\circ} \mathrm{C}$ & $30 \mathrm{~min}$ & 22.05 \\
\hline $300^{\circ} \mathrm{C}$ & $60 \mathrm{~min}$ & 21.17 \\
\hline $300^{\circ} \mathrm{C}$ & $90 \mathrm{~min}$ & 22.26 \\
\hline
\end{tabular}

\section{Conclusion}

Based on the study, it can be concluded that torrefaction is an effective pretreatment of Khaya senegalensis biomass in order to obtain desirable quality of biomass feedstock. The torrefied biomass contains much lower ash content that is good for thermal conversion and equipment. Furthermore, torrefaction increase the carbon content and amplify the calorific value. It was found that the best torrefaction condition for preparing good quality of Khaya senegalensis biomass feedstock is $300{ }^{\circ} \mathrm{C}$ of torrefaction temperature with more than 60 minutes torrefaction time.

\section{Acknowledgements}

Authors wishing to acknowledge assistance or encouragement and express the deepest appreciation from colleagues, special work by technical staff or financial support from Institute of Sustainable Agrotechnology (INSAT), Universiti Malaysia Perlis (UniMAP) and Faculty of Engineering Technology for the opportunity given and facilities provided to complete this research.

\section{References}

[1] Herbert, GM Joselin, and A. Unni Krishnan. "Quantifying environmental performance of biomass energy." Renewable and Sustainable Energy Reviews $59 \quad$ (2016): 292-308. https://doi.org/10.1016/i.rser.2015.12.254

[2] Sansaniwal, S. K., Pal, K., Rosen, M. A., \& Tyagi, S. K. (2017). Recent advances in the development of biomass gasification technology: A comprehensive review. Renewable and sustainable energy reviews, 72, 363-384. https://doi.org/10.1016/i.rser.2017.01.038

[3] Glithero, N. J., Paul Wilson, and Stephen J. Ramsden. "Optimal combinable and dedicated energy crop scenarios for marginal land." Applied Energy 147 (2015): 82-91. https://doi.org/10.1016/i.apenergy.2015.01.119

[4] Jiang, R., WANG, T. T., Jin, S. H. A. O., Sheng, G. U. O., Wei, Z. H. U., YU, Y. J., ... \& Hatano, R. (2017). Modeling the biomass of energy crops: Descriptions, strengths and prospective. Journal of integrative agriculture, 16(6), 11971210. https://doi.org/10.1016/S2095-3119(16)61592-7

[5] Suzuki, Kazunobu, Nobuyuki Tsuji, Yoshihito Shirai, Mohd Ali Hassan, and Mitsuru Osaki. "Evaluation of biomass energy potential towards achieving sustainability in biomass energy utilization in Sabah, Malaysia." Biomass and Bioenergy 97 (2017): 149-154. https://doi.org/10.1016/i.biombioe.2016.12.023

[6] Ky-Dembele, Catherine, Jules Bayala, Patrice Savadogo, Mulualem Tigabu, Per Christer Odén, and Issaka Joseph Boussim. "Comparison of growth responses of Khaya senegalensis seedlings and stecklings to four irrigation 
regimes." Silva Fennica 44, no. 5 (2010): 787-798. https://doi.org/10.14214/sf.121

[7] Abdullah, Rosazlin, Che Fauziah Ishak, Wan Rasidah Kadir, and Rosenani Abu Bakar. "Application of raw and composted recycled paper mill sludge on the growth of Khaya senegalensis and their effects on soil nutrients and heavy metals." International Journal of Agriculture and Biology 18, no. 1 (2016): 52-60. https://doi.org/10.17957/IJAB/15.0061

[8] Hupa, Mikko, Oskar Karlström, and Emil Vainio. "Biomass combustion technology development-lt is all about chemical details." Proceedings of the Combustion institute 36, no. 1 (2017): 113-134. https://doi.org/10.1016/i.proci.2016.06.152

[9] García, Roberto, Consuelo Pizarro, Antonio G. Lavín, and Julio L. Bueno. "Biomass sources for thermal conversion. Techno-economical overview." Fuel 195 (2017): 182-189. https://doi.org/10.1016/i.fuel.2017.01.063

[10] Bhutto, Abdul Waheed, Khadija Qureshi, Khanji Harijan, Rashid Abro, Tauqeer Abbas, Aqeel Ahmed Bazmi, Sadia Karim, and Guangren Yu. "Insight into progress in pre-treatment of lignocellulosic biomass." Energy 122 (2017): 724-745. https://doi.org/10.1016/i.energy.2017.01.005

[11] Chen, Wei-Hsin, Yi-Qing Zhuang, Shih-Hsien Liu, Tarng-Tzuen Juang, and Chi-Ming Tsai. "Product characteristics from the torrefaction of oil palm fiber pellets in inert and oxidative atmospheres." Bioresource technology 199 (2016): 367-374. https://doi.org/10.1016/i.biortech.2015.08.066

[12] Proskurina, Svetlana, Jussi Heinimö, Fabian Schipfer, and Esa Vakkilainen. "Biomass for industrial applications: The role of torrefaction." Renewable Energy 111 (2017): 265-274. https://doi.org/10.1016/j.renene.2017.04.015

[13] Isemin, Rafail, Alexander Mikhalev, Dmitry Klimov, Panagiotis Grammelis, Nikolaos Margaritis, Dimitrios-Sotirios Kourkoumpas, and Viktor Zaichenko. "Torrefaction and combustion of pellets made of a mixture of coal sludge and straw." Fuel 210 (2017): 859-865. https://doi.org/10.1016/i.fuel.2017.09.032

[14] Matali, S., N. A. Rahman, S. S. Idris, N. Yaacob, and A. B. Alias. "Lignocellulosic biomass solid fuel properties $\begin{array}{lllll}\text { enhancement } \quad \text { via } \quad \text { torrefaction." Procedia } & \text { Engineering } 148 & \text { (2016): }\end{array}$ https://doi.org/10.1016/i.proeng.2016.06.550

[15] Matali, S., N. A. Rahman, S. S. Idris, N. Yaacob, and A. B. Alias. "Lignocellulosic biomass solid fuel properties $\begin{array}{llllll}\text { enhancement } \quad \text { via } & \text { torrefaction." Procedia } & \text { Engineering } 148 & \text { (2016): }\end{array}$ https://doi.org/10.1016/i.proeng.2016.06.550

[16] Castellano, J. M代, M. Gómez, M. Fernández, L. S. Esteban, and J. E. Carrasco. "Study on the effects of raw materials composition and pelletization conditions on the quality and properties of pellets obtained from different woody and non woody biomasses." Fuel 139 (2015): 629-636. https://doi.org/10.1016/i.fuel.2014.09.033

[17] Johansson, Ann-Christine, Henrik Wiinikka, Linda Sandström, Magnus Marklund, Olov GW Öhrman, and Jimmy Narvesjö. "Characterization of pyrolysis products produced from different Nordic biomass types in a cyclone pilot plant." Fuel processing technology 146 (2016): 9-19. https://doi.org/10.1016/j.fuproc.2016.02.006

[18] Chen, Dengyu, Zhongcheng Zheng, Kexin Fu, Ze Zeng, Jiajia Wang, and Mengting Lu. "Torrefaction of biomass stalk and its effect on the yield and quality of pyrolysis products." Fuel 159 (2015): 27-32. https://doi.org/10.1016/j.fuel.2015.06.078

[19] Kajina, Wanida, Patrick Rousset, Wei-Hsin Chen, Thitima Sornpitak, and Jean Michel Commandré. "Coupled effect of torrefaction and blending on chemical and energy properties for combustion of major open burned agriculture residues in Thailand." Renewable energy 118 (2018): 113-121. https://doi.org/10.1016/j.renene.2017.11.006

[20] Hansted, Ana Larissa Santiago, Thiago Aguiar Cacuro, Gabriela Tami Nakashima, Vladimir Eliodoro Costa, Hiroyuki Yamamoto, and Fábio Minoru Yamaji. "Use of a lignocellulosic residue as solid fuel: The effect of ash content in the energy potential." Industrial Crops and Products $116 \quad$ (2018): $209-214$. https://doi.org/10.1016/i.indcrop.2018.02.042

[21] Huang, Yu-Fong, Pei-Hsin Cheng, Pei-Te Chiueh, and Shang-Lien Lo. "Leucaena biochar produced by microwave torrefaction: Fuel properties and energy efficiency." Applied energy 204 (2017): 1018-1025. https://doi.org/10.1016/j.apenergy.2017.03.007

[22] Tumuluru, Jaya Shankar. "Effect of deep drying and torrefaction temperature on proximate, ultimate composition, and heating value of 2-mm lodgepole pine (Pinus contorta) Grind." Bioengineering 3, no. 2 (2016): 16. https://doi.org/10.3390/bioengineering3020016

[23] Cahyanti, Margareta Novian, Tharaka Rama Krishna C. Doddapaneni, and Timo Kikas. "Biomass torrefaction: An overview on process parameters, economic and environmental aspects and recent advancements." Bioresource technology 301 (2020): 122737. https://doi.org/10.1016/i.biortech.2020.122737

[24] Wannapeera, Janewit, and Nakorn Worasuwannarak. "Examinations of chemical properties and pyrolysis behaviors of torrefied woody biomass prepared at the same torrefaction mass yields." Journal of Analytical and Applied Pyrolysis 115 (2015): 279-287. https://doi.org/10.1016/i.jaap.2015.08.007

[25] Van der Stelt, M. J. C., Heiko Gerhauser, J. H. A. Kiel, and K. J. Ptasinski. "Biomass upgrading by torrefaction for the production of biofuels: A review." Biomass and bioenergy 35, no. 9 (2011): 3748-3762. 
https://doi.org/10.1016/i.biombioe.2011.06.023

[26] Park, Junyeong, Jiajia Meng, Kwang Hun Lim, Orlando J. Rojas, and Sunkyu Park. "Transformation of lignocellulosic biomass during torrefaction." Journal of Analytical and Applied Pyrolysis 100 (2013): 199-206. https://doi.org/10.1016/i.jaap.2012.12.024 